\title{
First record of a larva of the dipteran genus Aphrosylus HALIDAY, 1851 (Dolichopodidae) from the Egyptian Mediterranean Sea
}

\author{
Khaled MaHMOUd ABDElSAlam* \\ National Institute of Oceanography and Fisheries, Alexandria, Egypt
}

\begin{abstract}
The present investigation is the first to provide systematic information about marine dipteran larvae of the genus Aphrosylus HALIDAY, 1851 (Dolichopodidae), collected from the Egyptian Mediterranean Sea. During May 2017, fouling samples were scraped from natural coastal rocks in the Abu Qir area, east of Alexandria city, Egypt. Only two larvae of Aphrosylus sp. were recorded. This is a new record for the Egyptian Mediterranean Sea fauna. A concise description supplied with drawings, habitat, and distribution of the recorded genus is provided.
\end{abstract}

KEY WORDS: Aphrosylus, Dolichopodidae, Systematics, First record, Mediterranean Sea, Egypt.

\section{INTRODUCTION}

The Dolichopodidae (Long-legged flies) is a distinctive and quite large family of the order Diptera, with more than 150 genera and about 6000 described species worldwide (MCALPINE \& WOOD 1989). PAPE et al. (2011) expanded the biodiversity of the family to include 268 genera and 7358 species. According to GRICHANOv (2018), the family Dolichopodidae now contains 252 extant and 27 fossil genera, and about 8211 species, including 230 doubtful species, distributed around the world. Dolichopodid adults and larvae are mainly predacious (GRICHANOV 2016a).

CHENG (1976) studied the Diptera of marine environments and mentioned that some flies breed in the littoral or intertidal zone. They include Chironomidae (Thalassomya SCHINER, 1856, Psamathiomya DeBY, 1889, Halocladius HIRVENOJA, 1973, Clunio HALIDAY, 1855 and Thalassosmittia STRENZKE \& REMmeRT, 1957), Tipulidae (Limonia

\footnotetext{
* Corresponding author: Kh.abdelsalam@gmail.com
} 
(Geranomyia) unicolor HALIDAY, 1833) and Dolichopodidae (Aphrosylus HALIDAY, 1851, Dolichopus nubilis MEIGEN, 1824, Machaerium HALIDAY, 1832, Hydrophorus oceanus MACQUART, 1838, Hygrocoleuthus LOEW, 1857, Rhaphium consobrinum ZETTERSTEDT, 1843). All species of Aphrosylus appear to be intertidal in habitat. SMITH (1989) reported the unusual wide salinity tolerance of Dolichopodidae species. Larvae of Dolichopodidae are found in damp substrates (in sand, mud, decaying vegetation, under tree roots, and sometimes on sea shores), and are predacious (MEUFFELS et al. 2017).

Some remarkable studies on Dolichopodidae in the Palearctic region (which covers northern Africa, Europe, the northern part of Arabia and all of Asia north of the Himalayas) have been done. GRICHANOV $(2007 \mathrm{a}, 2011)$ prepared keys to the east Mediterranean species and Palaearctic genera of Dolichopodidae. Although a database of the European fauna has been compiled by POLLET (2004), only POLLET (2001) and KeCHEV (2012) have investigated the distribution of dolichopodids in Europe.

Dolichopus LATREILLE, 1796, represented by 646 species, is the most diverse genus of the family Dolichopodidae; in contrast, the genus Aphrosylus HALIDAY, 1851 comprises a little more than 30 valid species (GRICHANOV 2018). Species of the genus Aphrosylus are fairly large to extremely small, breeding in intertidal habitats around coasts. In the males, the spoon-shaped palps are 'silvered' on one side; the male flies thus appear to be handling a couple of small flag lights as they keep running across the wet rocks when they get the light intermittently (D'ASSIS FONSECA 1978).

In Egypt, studies of Dolichopodidae go back to BECKER (1902, 1910). BECKER (1902) studied the Egyptian Diptera and listed 24 species of adult dolichopodids, 14 of which were new species. The recorded species were variably distributed in different areas of Egypt, including Cairo, Alexandria, Birket Karun, Suez, Fayoum, Assiut, Luxor and Aswan. The new species included Thinophilus indigenus BECKER, 1902, T. modestus BECKER, 1902, T. quadrimaculatus BECKER, 1902, Paralleloneurum cilifemoratum BECKER, 1902, Syntormon pallipes (FABRICIUS, 1794), S. triangulipes BECKER, 1902, Asyndetus connexus (BECKER, 1902), A. separatus (BECKER, 1902), Trigonocera rivosa BECKER, 1902, Hydrophorus praecox (LeHMANN, 1822), Sciapus adumbratus BECKER, 1902, Tachytrechus tessellatus (MACQUART, 1842), Dolichopus callosus BECKER, 1902 and D. flavocrinitus BECKER, 1902. Later, BECKER (1910) investigated the Dipteran insects of southern Arabia and the island of Socotra. He recorded 7 species of adult dolichopodids, three of them in Egypt (Port Said): Thinophilus argyropalpis (a new species), Hydrophorus praecox and Trigonocera rivosa.

PARENT (1925) studied the adults of Dolichopodidae in the collection of Mr. EFFLATOUN, and he gave some new species, in addition to a list of the already known ones: Dolichopus callosus, D. flavocrinitus, Tachytrechus tessellatus, Thinophilus achilleus MILK, 1900, T. flavipalpis (ZETTERSTEDT, 1843), T. indigenus, T. quadrimaculatus, 
Asyndetus connexus, A. separatus, Trigonocera rivosa, Chrysotus suavis LoEW, 1857, Thrypticus bellus LOEW, 1869, Syntormon pallipes, Sciapus adumbratus and Hydrophorus praecox, distributed in different areas of Egypt, including Alexandria, Kerdacé, Cleopatra (Alexandria), Fayoum, Giza and Shoubra. The eight new species first described by PARENT (1925) were Medetera albescens (from Mariout), M. albisetosa (Suez road), Asyndetus chaetifemoratus (Baharia Oasis), A. dubius (Fayoum), Hydrophorus rufinasutus (AbuRowash), Sciapus vicinus (Rafa-Sinai N.E.), Dolichopus efflatouni (Baharia Oasis) and Aphrosylus parcearmatus (Abou-Kir). PARENT (1929) also investigated the adults of Dolichopodidae from the Halaib region (SE Egypt), describing nine new species from there: Medetera araneipes (Gebel Elba), Asyndetus albifrons (Bir Abrag - South Eastern Desert), A. albifacies (Mt. Halaib), Thinophilus spinulosus (Halaib - Red Sea Coast), T. maculatus, T. tinctus, T. atritarsis (these three species from Bir Abrag - South Eastern Desert), Argyrochlamys cavicola (Mersa Halaib) and Tachytrechus planitarsis (Gebel ElbaSouth Eastern Desert).

Recently, GRICHANOv (2007a) listed 59 species of adult Dolichopodidae from Egypt. The list comprised species from the following genera: Acropsilus LOEW, 1869 (1 species), Asyndetus Loew, 1869 (7), Chrysotus MeIgen, 1824 (2), Trigonocera BeCKer, 1902 (1), Argyrochlamys LAMB, 1922 (1), Dolichopus (3), Sybistroma GERMAR, 1817 (2), Tachytrechus HALIDAY in WALKER, 1851 (2), Aphrosylus (1), Hydrophorus FALLÉN, 1823 (4), Paralleloneurum BeCKer, 1902 (1), Thinophilus WAHLBerg, 1844 (12), Medetera FISCHER VON WALDHEIM, 1819 (9), Thrypticus GERSTÄCKER, 1864 (1), Xanthochlorus LOEW, 1857 (1), Sciapus Zeller, 1842 (3), Lamprochromus MILK, 1878 (1), Micromorphus MiLK, 1878 (2), Sympycnus LOEW, 1857 (1), Syntormon LOEW, 1857 (3) and Teuchophorus LOEW, 1857 (1). Subsequently, Grichanov (2007b) published new records of adult Dolichopodidae from the greater Middle East region: five species from Cyprus, eight from the Sinai peninsula (Egypt), two from Rhodes, 11 from Crete, 14 from Turkey and 58 from Israel. The eight new records of Dolichopodidae from Egypt (Sinai) included Hydrophorus praecox; Medetera pallipes (ZETTERSTEDT, 1843); M. pavlovskii Negrobov, 1972; M. truncorum MeIGEN, 1824; Micromorphus aereus (VAILlant, 1953); Syntormon pallipes; Tachytrechus planitarsis BECKER, 1907; and T. tessellatus. More recently, GRICHANOV (2016b) described the new species of Cyrturella nigrosetosa, which was collected from Egypt: Sinai, Ein Qsaib.

On the other hand, there have been very few studies of marine dipteran larvae from Egyptian waters. ABDELSALAM (2017) published the first record of a chironomid larva (Clunio sp.1) from Hurghada, Egyptian Red Sea, which might belong to a species new to science. With that exception, no larval stage of Dolichopodidae has been recorded in Egypt, so the aim of the present study is to fill this gap: it describes and provides some taxonomic 
comments on the marine dolichopodid larvae of Aphrosylus sp., recorded for the first time from the Egyptian Mediterranean coast.

\section{MATERIALS AND METHODS}

On 1 May 2017, fouling samples were scraped from natural coastal rocks in the Abu Qir area, east of Alexandria city, Egypt (Fig. 1).

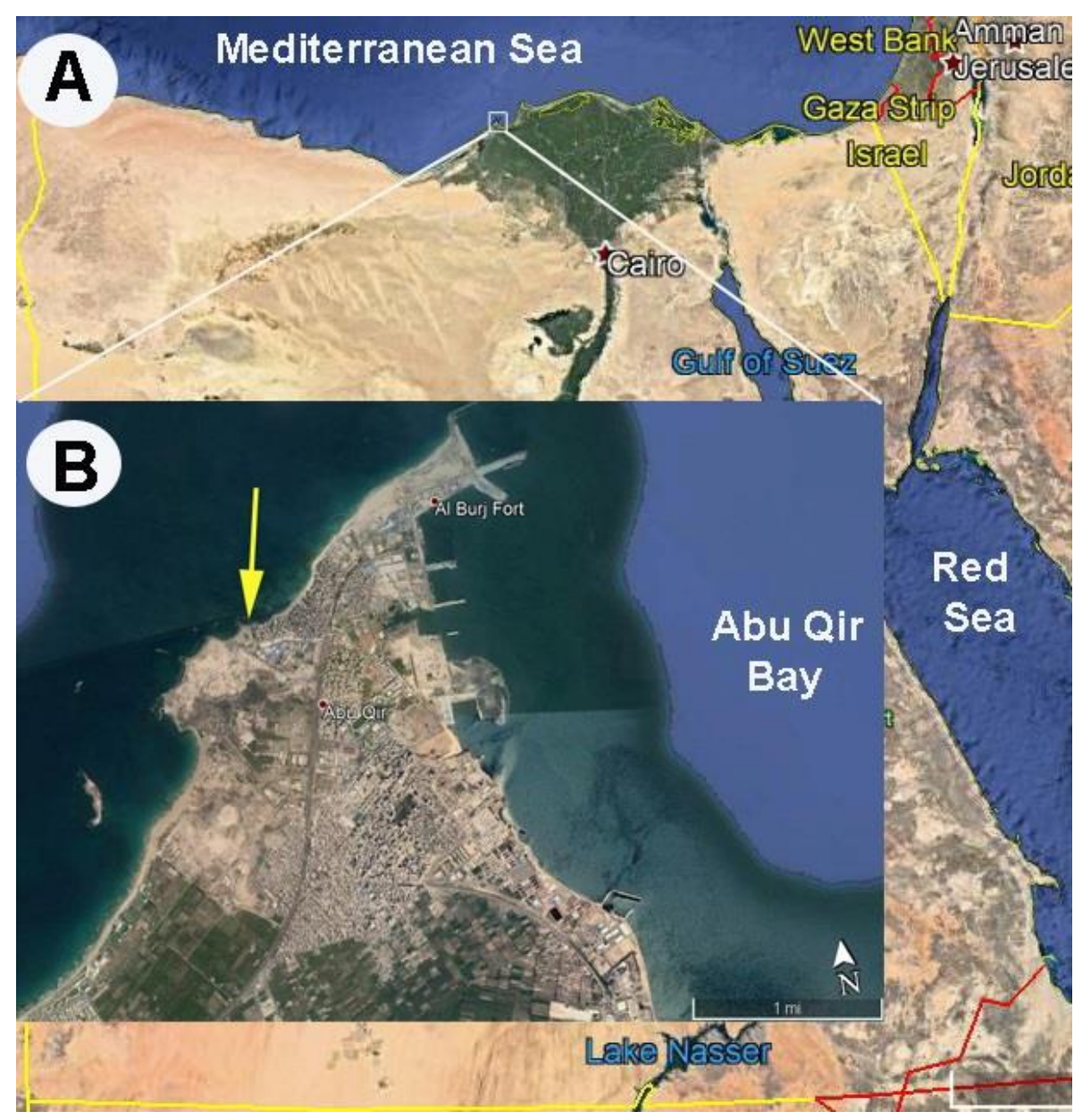

Fig. 1. Map of Egypt (A); the arrow shows the location of the sampling site in the Abu Qir area (B). 
The sampling site is located at $31^{\circ} 19^{\prime} 11.72^{\prime \prime} \mathrm{N}$ and $30^{\circ} 03^{\prime} 12.20^{\prime \prime} \mathrm{E}$. The fouling specimens were preserved in $10 \%$ formalin solution. In the laboratory, examination of these samples revealed just two dipteran larvae, which were isolated for identification.

The larvae were examined under a stereo-zoom microscope. Illustrations of some anatomical parts were made under a dissecting microscope equipped with a camera lucida. Microphotographs were taken under a light microscope with a mounted Nikon digital camera (Model D3200).

The head capsules of the larvae were prepared and examined after brief immersion in cool $\mathrm{NaOH}$ and preserved in glycerin. Some relevant scientific publications were consulted for the identification of specimens (e.g. WHEELER 1897; ROUBAUD 1903; SAUNDERS 1928; PARENT 1938; SMITH 1989; POULDING 1998). The terminology of the larval morphological features generally follows that of TESKEY (1981).

\author{
RESULTS \\ Class: Insecta \\ Order: Diptera \\ Suborder: Brachycera \\ Family: Dolichopodidae \\ Subfamily: Hydrophorinae \\ Genus: Aphrosylus HALIDAY, 1851 \\ Aphrosylus sp. \\ Figs (2-8)
}

\title{
Materials
}

Only two larvae of Aphrosylus sp. were found to be associated with the marine fouling samples, which were collected from natural coastal rocks in the Abu Qir area. The fouling community is composed mainly of large numbers of barnacles (Amphibalanus amphitrite DARWIN, 1854 and Perforatus perforatus BRUGUIÈRE, 1789) and the mytilid bivalve Brachidontes pharaonis (FISCHER P., 1870). The two larvae were 5.41 and $3.63 \mathrm{~mm}$ in length. 


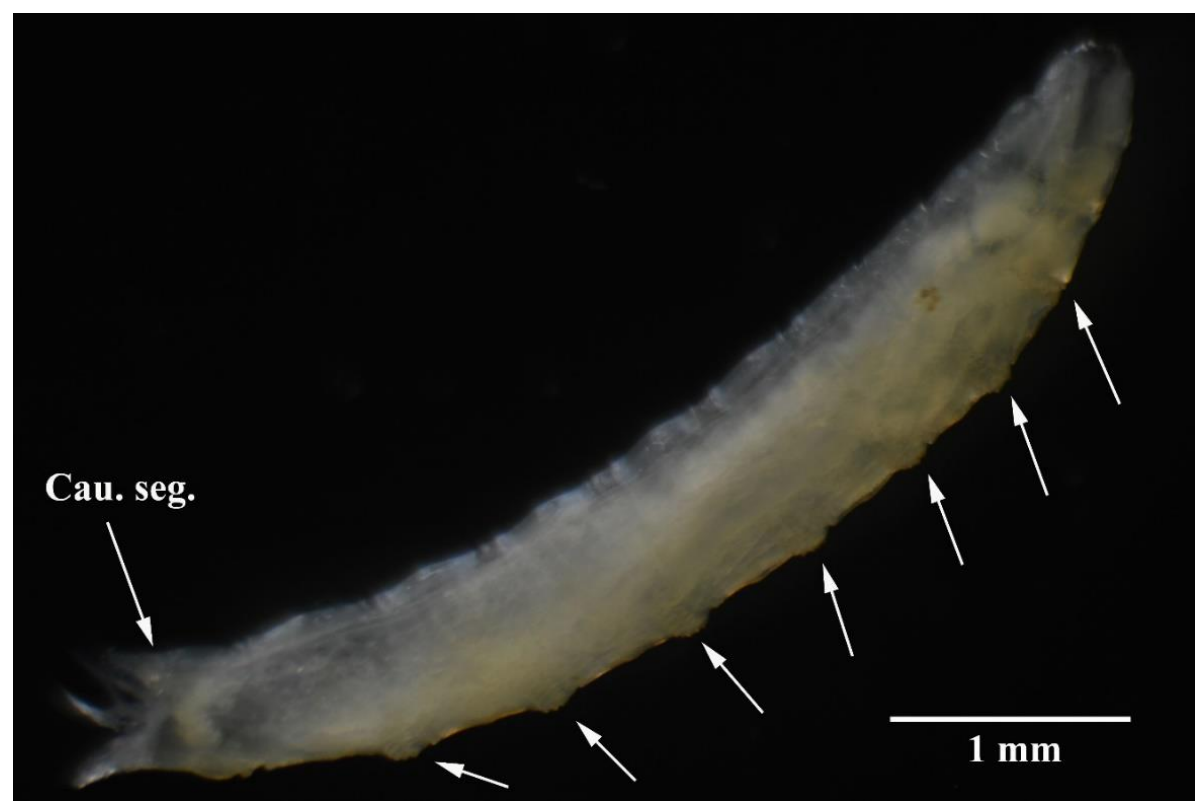

Fig. 2. Larva of Aphrosylus sp.; length $=5.41 \mathrm{~mm}$; the arrows show the ventral welts of the abdominal segments; Cau. seg., Caudal segment.

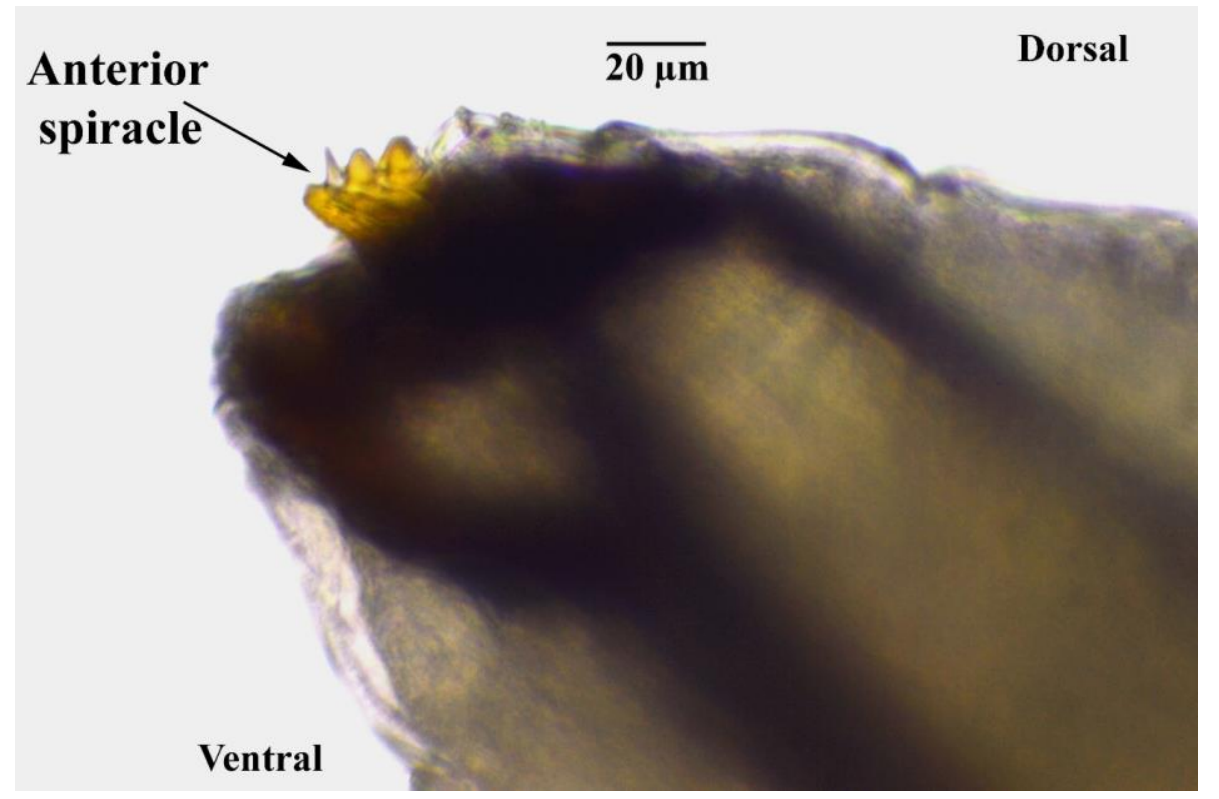

Fig. 3. Lateral view of the anterior tip of the larval head showing the anterior spiracle; larval length $=5.41 \mathrm{~mm}$. 


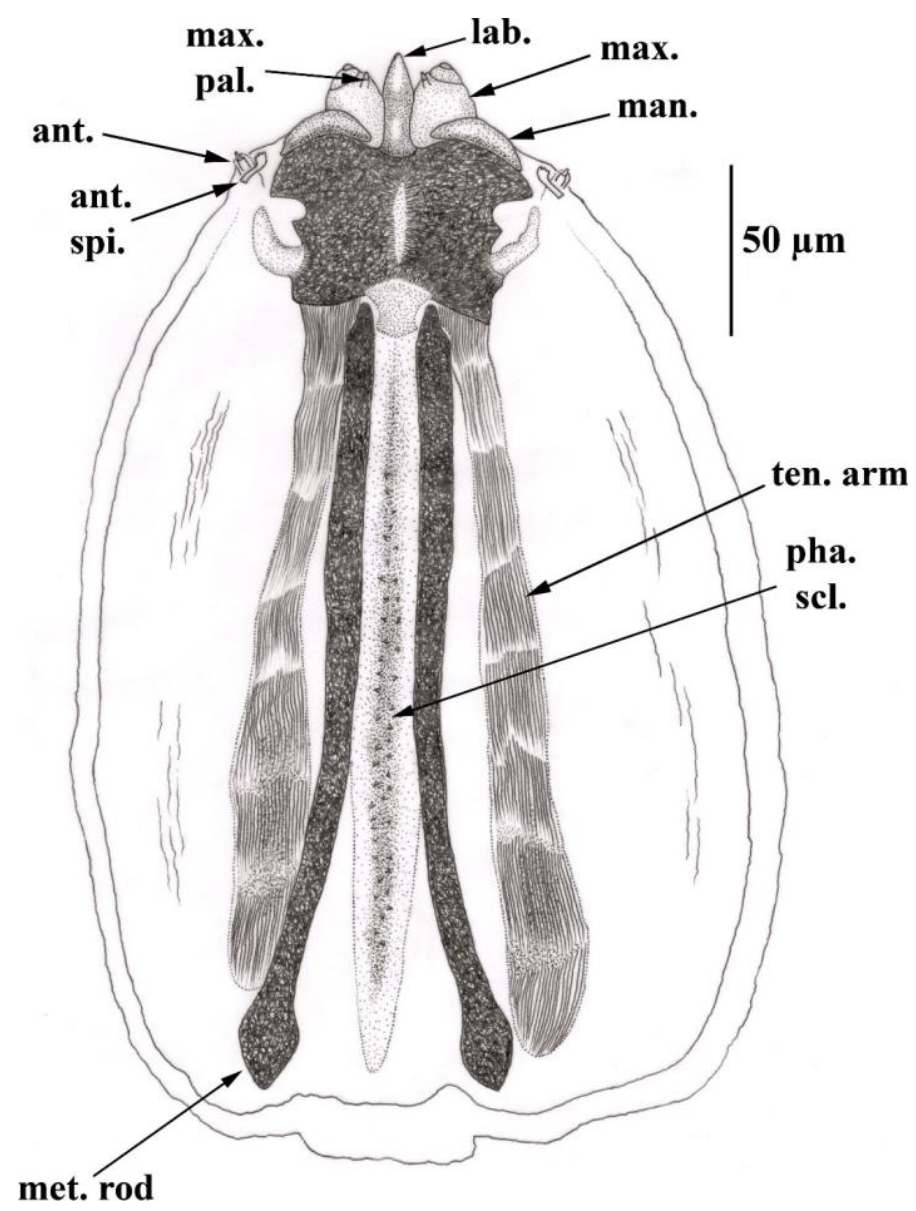

Fig. 4. Dorsal view of the larval head skeleton, showing different structures; ant., antenna; ant. spi., anterior spiracle; lab., labrum; man., mandible; max., maxilla; max. pal., maxillary palpus; met. rod, metacephalic rod; pha. scl., pharyngeal sclerite; ten. arm, tentorial arm; larval length $=3.63 \mathrm{~mm}$.

\section{Description}

Larvae whitish, cylindrical and relatively slender; 11 segments, excluding the head. Anterior end tapering. Distinct prolegs absent, but with distinct creeping welts on abdominal segments 1 to 7 (Fig. 2). Breathing apparatus amphipneustic, with two pairs of separated stigmas (tracheal spiracles): anterior pair located on each side of prothoracic segment (Fig. 3), posterior pair on last abdominal segment (Fig. 8). Posterior end of larva (segment 11) truncate, with more than four primary lobes (Fig. 5). 


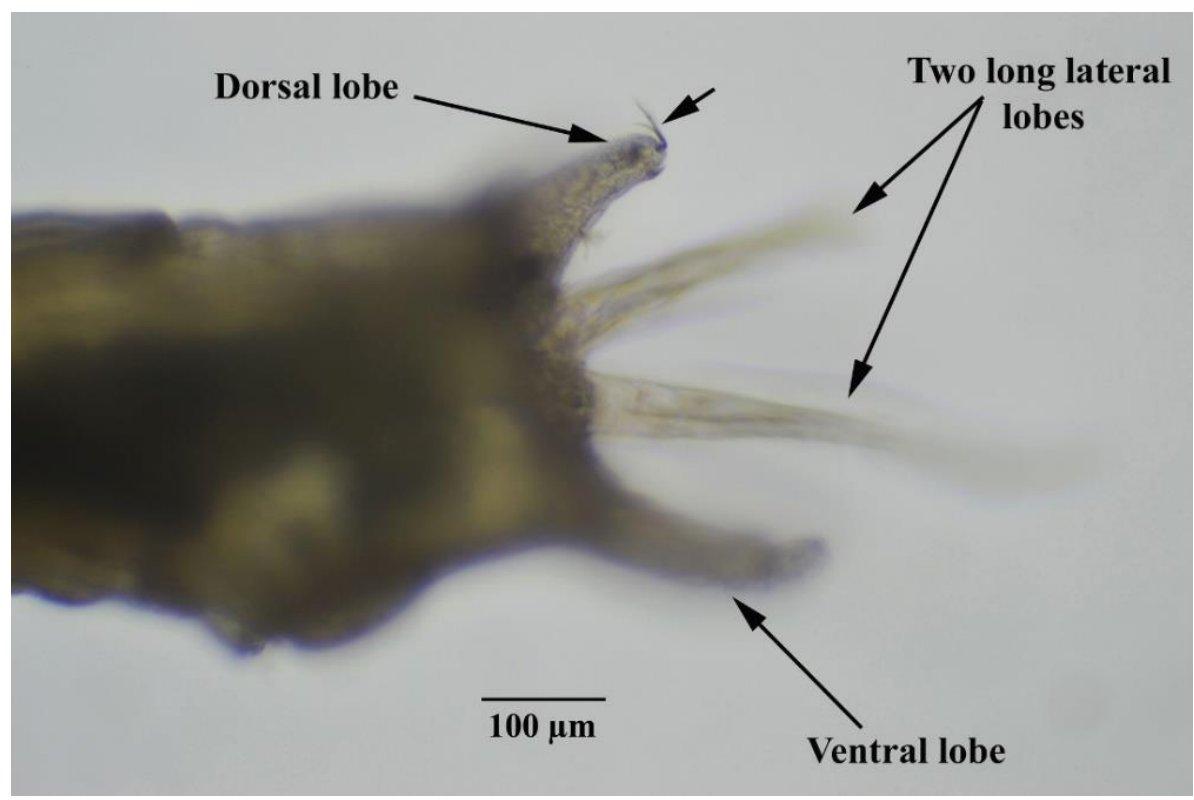

Fig. 5. Lateral view of the last abdominal segment showing the primary lobes (dorsal and ventral) and the two long lateral lobes; the arrows show the setae of the dorsal lobe; larval length $=3.63 \mathrm{~mm}$.

Head \& mouth parts. Head pseudocephalic (reduced and retracted into thorax), tapered; with lateral pair of very short (two articles) antennas; at anterior level of antennas, a pair of maxilla provided with maxillary palps are situated closer to each other (Fig. 4). Head with short dorsal chitinous plate, curved; prolonged posteriorly into two apically expanded or spatulate metacephalic rods; two others (tentorial arms), parallel, comparable to them, ventral; and an inner odd plow (pharyngeal sclerite), in a vertical blade coarsely sawed. Labrum extends forward like a rostrum. As in most brachyceran Diptera, larval mandible consists of four components: distal hook, two connecting sclerites and a ventral or basal sclerite. Mandibles move parallel to each other in the ventral plane.

Thorax. Attached directly to head, i.e. the rear fractions of the larval head capsule extend into the prothorax. It is formed of three gradually enlarging segments (prothorax, mesothorax and metathorax), telescoping into one another, as it were; without anterior ventral creeping welts (Fig. 6). 


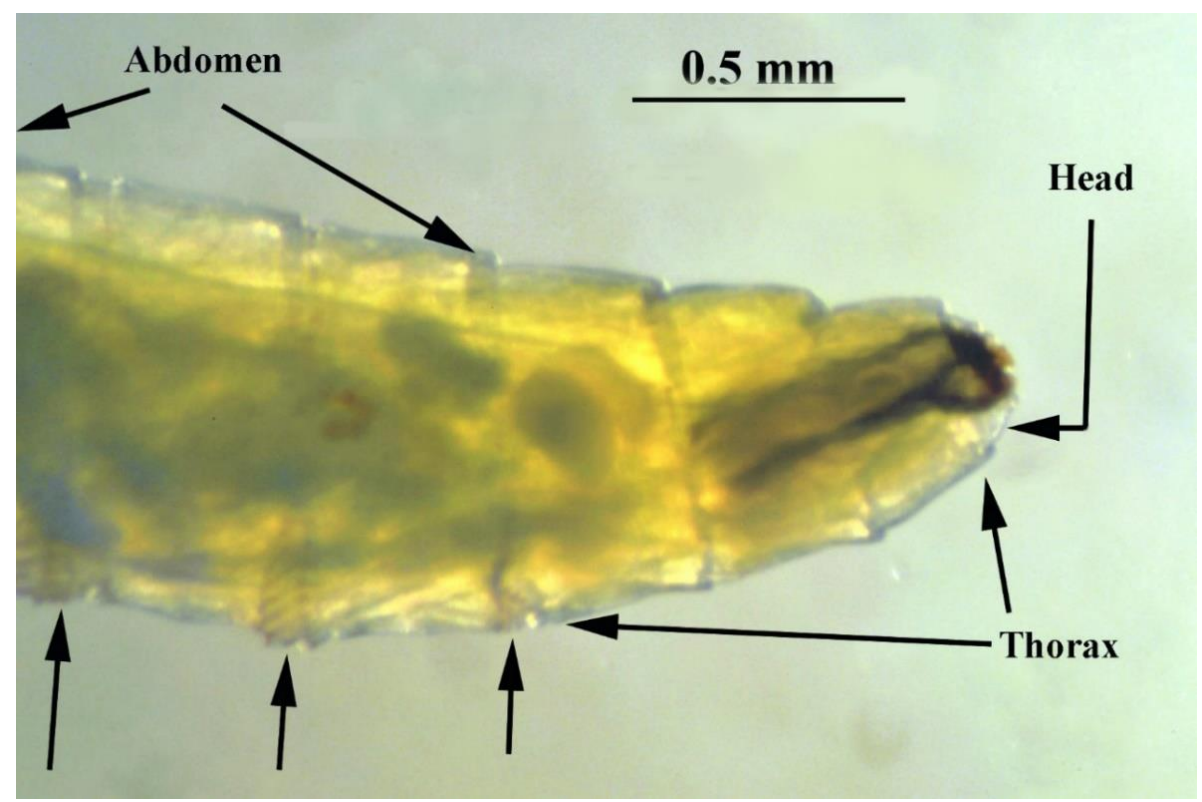

Fig. 6. Lateral view of larva, showing different regions of the body; the arrows show the ventral abdominal welts; larval length $=5.41 \mathrm{~mm}$.

$100 \mu \mathrm{m}$

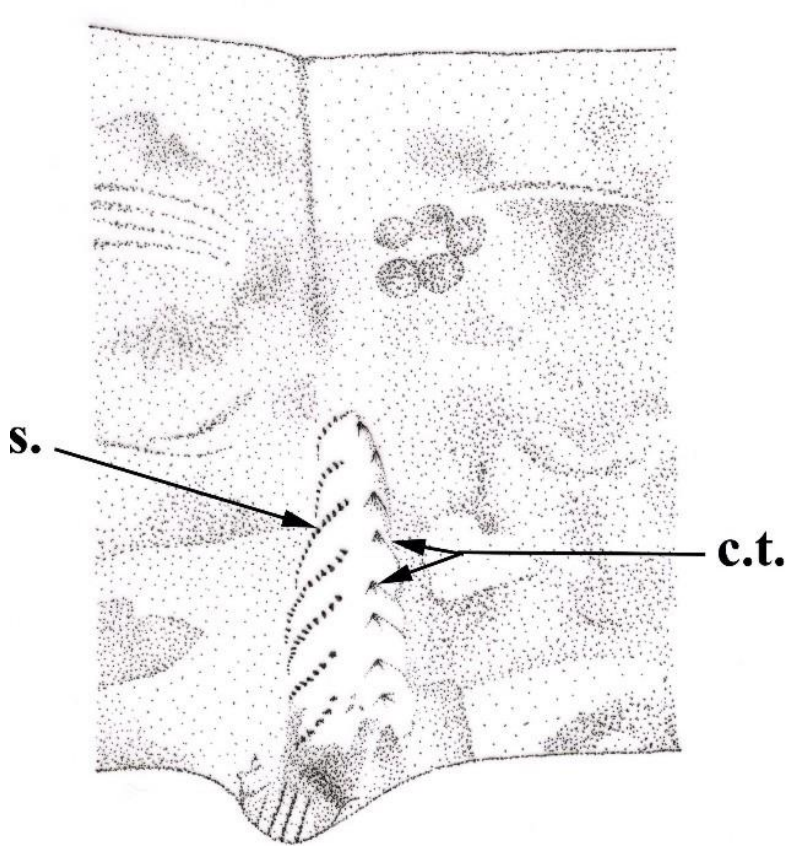

Fig. 7. Ventral abdominal welt showing fine structures; c.t., cuticular teeth; s., spinules; larval length $=5.41 \mathrm{~m}$. 


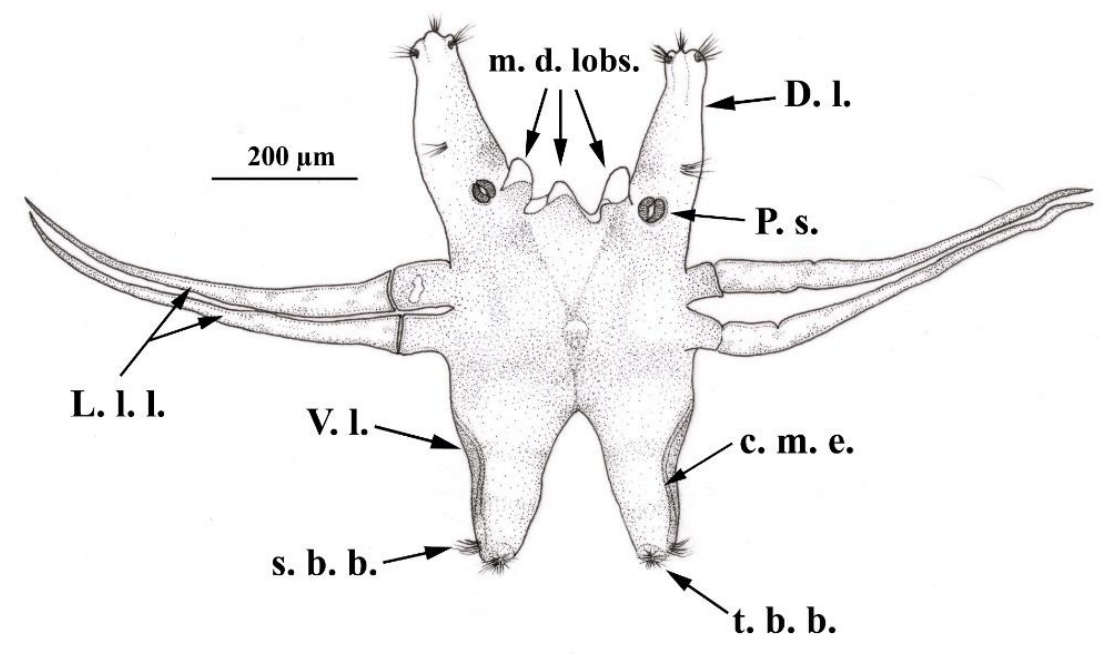

Fig. 8. Last abdominal segment (spiracular disc) showing different types of lobes and lobules; c. m. e., curved marginal edge; d. 1., dorsal lobe; 1. 1. 1., long lateral lobes; m. d. lobs., medio-dorsal lobules; p. s., posterior spiracle; s. b. b., sub-terminal bunch of bristles; t. b. b., terminal bunch of bristles; v. 1., ventral lobe; larval length $=5.41 \mathrm{~mm}$.

Abdomen. Eight segments, each one of segments 1-7 with a pair of ventral creeping welts on the anterior margin. These welts bear cuticular teeth and spinules, which are arranged in transverse and oblique rows (Fig. 2, 7).

Caudal end. Terminal abdominal segment (segment 11), conical, prolonged by dentiform and mobile lobes, arranged regularly at its free edge as follows: three mediodorsal barely scarred lobules; two latero-dorsal lobes, bearing at their base, on the internal side, the posterior spiracles, three bunches of setae at their distal rim, and one bunch of medial setae on their proximal rim; four lateral long lobes, in two slender pairs; and two large ventral lobes, juxtaposed, nearly double the length of latero-dorsal lobes, with curved marginal edge, bearing two bunches of bristles (terminal \& sub-terminal), and anal orifice at their base. The curved marginal edge almost ends at the sub-terminal bunch of bristles (Fig. 8).

\section{Habitat and distribution}

RoubAud (1903) found larvae of Aphrosylus in colonies of the barnacle Semibalanus balanoides (LINNAEUS, 1767) (formerly Balanus balanoides) which he collected from the 
Atlantic coast of France. He considered the relationship between the two organisms to be parasitic. In the current study, the larvae were associated with marine fouling (large numbers of barnacles including Amphibalanus amphitrite and Perforatus perforatus) on the natural rocks in the Abu Qir area.

Data on the distribution of the genus Aphrosylus in the Caucasus and eastern Mediterranean were compiled by GRICHANOV (2007a) and include the following species: Aphrosylus ferox HALIDAY, 1851 [Russia (Crimea); W Europe from Spain to Norway]; Aphrosylus fuscipennis STROBL, 1909 [Bulgaria; Spain]; Aphrosylus parcearmatus PARENT, 1925 [Egypt: Sinai; Israel; Turkey]; Aphrosylus piscator LICHTWARDT, 1902 [Bulgaria?, Croatia ("Novi")]; Aphrosylus raptor HALIDAY, 1851 ["South of the European part of the USSR"; Canary Is., France, Great Britain, Ireland, Morocco, Portugal, Spain]; Aphrosylus schumanni Negrobov, 1979 [Israel, Lebanon?, Crete ("Kandia")]; Aphrosylus venator LOEW, 1857 [Bulgaria; Ukraine: Crimea; "Yugoslavia", Hungary, Italy, France, Madeira, Selvagens Is., Spain]. It is evident that only Aphrosylus parcearmatus was reported from Egypt: Abou-Kir area (PARENT 1925).

However, the present record of marine larvae of Aphrosylus sp. is the first from the Abu Qir area, Alexandria, representing an addition to the biodiversity of the Egyptian Mediterranean Sea fauna.

\section{DISCUSSION}

A helpful and distinctive character for identifying most Dolichopodidae from other brachyceran larvae (particularly Empididae, with which they are frequently found), is the swollen posterior tip of each of the metacephalic rods of the mouthparts. Other larval and pupal contrasts were explored by DYTE (1967).

It should be mentioned that most immature stages of Dolichopodidae are poorly known, and more larvae have not been adequately described. TESKEY (1981) gave a general comprehensive investigation about the morphology and terminology of Dipteran larvae. However, ROBINSON \& VOCKEROTH (1981) proposed a key for distinguishing between 12 genera of dolichopodid larvae in the Nearctic area, but it did not include Aphrosylus. Moreover, there is no description for larvae of the type locality (Aphrosylus parcearmatus) from Egypt.

Only a few authors have described the immature stages of Dolichopodidae. WHEELER (1897) studied the marine fauna of Monterey, California. This author described the larvae of the genus Aphrosylus, most likely the hatchlings of a common species A. praedator WHEELER, 1897, indicating that "they are flickering white, decreasing to a point anteriorly, and less quickly to the truncated posterior end, which is encompassed by nine straightened 
lobes." He only illustrated the lateral view of the full grown larva of Aphrosylus. Meanwhile, the last abdominal segment (spiracular disc) of A. praedator was illustrated by SAUNDERS (1928). At present, this species is placed in the genus Paraphrosylus. DyTE (1959) also provided a diagram of a larva of Aphrosylus sp., which differed from all of the four British species. On the other hand, WILLIAMS (1939) illustrated a larva of the Hawaiian marine Cymatopus acrosticalis PARENT, 1937 (now in the genus Conchopus TAKAGI, 1965) with nine almost rounded lobes. Nevertheless, RoubAUD (1903) gave a description of marine larvae of Dolichopodidae attributed to the genus Aphrosylus, which were collected from the Cape of the Hague, Atlantic coast, France. Poulding (1998) indicated that the larvae found by RoUBAUD (1903) were identified as Aphrosylus celtiber HALIDAY, 1855.

ROUBAUD (1903) investigated in more detail the structures of both cephalic and caudal extremities, but also without any illustrations. In the present study, the caudal segment has three medio-dorsal lobules, two latero-dorsal lobes, four long lateral lobes (in two pairs), and two large ventral, juxtaposed lobes, i.e. a total of 8 lobes and 3 lobules. This is clearly shown in the diagrammatic illustration of the spiracular disc using the camera lucida.

Beside the resemblance between RouBAUD's (1903) description and the present study of the spiracular disc of Aphrosylus sp. in having 8 lobes and 3 lobules, the present drawing shows more details, such as 1) each of the latero-dorsal lobes, bearing three bunches of setae at its distal rim, and one bunch of medial steae on its proximal rim, and 2) each of the ventral lobes, having a curved marginal edge and bearing two bunches of bristles (terminal and sub-terminal).

Although the structure of the present larva resembles Aphrosylus celtiber HALIDAY, 1855 very closely, the identification of the species cannot be confirmed, without collecting a larva together with the adult stage at the same site, so it is safer to refer to it as Aphrosylus sp.

According to Grichanov (2018), the genus Aphrosylus HALIDAY, 1851 comprises more than 30 valid species, but the larval stages of most species have not been adequately illustrated. This emphasises the importance of morphologically characterizing the larval stages of this genus in order to make meaningful comparisons between different species, even if the adult stage is not available. Thus, comprehensive studies on Egypt's sea coasts are required in order to extend our knowledge of marine insect larvae.

\section{REFERENCES}

AbDElSalam Kh.M. 2017. The genus Clunio Haliday, 1855 from Egypt (Hurghada, Red Sea) with a description of the larva of Clunio sp.1 (Diptera, Chironomidae, Orthocladiinae). Polish Journal of Entomology, 86 (1): 39-47. 
BECKER Th. 1902. Ägyptische Dipteren gesammelt und beschrieben. Mitteilungen aus dem Zoologischen Museum in Berlin, 2 (2): 1-66.

BECKER Th. 1910. Dipteren aus Südarabien und von der Insel Sokótra. Denkschriften der Akademie der Wissenschaften in Wien, 71: 131-160.

Cheng L. 1976. Marine Insects. North-Holland Publishing Company, Amsterdam - Oxford.

D'Assis FonSECA E.C.M. 1978. Handbooks for the identification of British insects, Volume 9 part 5: Diptera, Orthorrhapha, Brachycera, Dolichopodidae. Royal Entomological Society of London, London.

DyTE C.E. 1959. Some interesting habitats of larval Dolichopodidae (Diptera). Entomologist's Monthly Magazine, 95: 139-143.

Dyte C.E. 1967. Some distinctions between the larvae and pupae of the Empididae and Dolichopodidae (Diptera). Proceedings of the Royal Entomological Society, London (A), 42 (7-9): 119-128.

Grichanov I. 2007a. A checklist and keys to Dolichopodidae (Diptera) of the Caucasus and East Mediterranean. VIZR RAAS, St. Petersburg.

GRICHANOv I. 2007b. New records of Dolichopodidae (Diptera) from the Middle East. International Journal of Dipterological Research, 18 (3): 141-153.

Grichanov I. 2011. A brief synopsis of Palaearctic genera of the family Dolichopodidae (Diptera). Ukrainska Entomofaunistyka, 2 (2): 11-40.

GRICHANOV I. 2016a. Review of faunal investigation of predatory flies of the family Dolichopodidae (Diptera) in Iran. Acta Biologica Sibirica, 2 (4): 11-14.

Grichanov I. 2016b. A new species of Cyrturella Collin, 1952 (Diptera: Dolichopodidae) from Egypt. Caucasian Entomological Bulletin, 12 (1): 171-173.

GRICHANOV I. 2018. A check list of species of the family Dolichopodidae (Diptera) of the World arranged by alphabetic list of generic names. Internet: http://dolicho.narod.ru/Genera3.htm (Accessed: 1 September 2018)

HALIDAY A.H. 1851. Diptera. Empididae. Dolichopodidae. Syrphidae. [in:], F. WALKER (ed.). Insecta Britannica, Diptera. Volume 1. (q.v.). Reeve and Benham, London, 1-9, 85-144, 144-221, 234-303.

Haliday A. H. 1855. Descriptions of insects figured, and references to plates illustrating the notes on Kerry insects. Natural History Review, 2: 59-64.

KeChev M. 2012. Diversity of Long-Legged Flies (Diptera: Dolichopodidae) in Gradina Floodplain Forest, Bulgaria. Acta Zoologica Bulgarica, Supplement 4: 43-46.

McAlpine J.F. (ed.), Wood D.M. 1989. Manual of Nearctic Diptera Volume 3. Monograph No. 32. Biosystematics Research Centre, Ottawa.

Meuffels H.J.G., Beuk P.L.TH., van DeR Goot V.S. 2017. Family Dolichopodidae. [in:] P.L.TH. BEUK (ed.). Checklist of the Diptera of the Netherlands. Internet: http://www.dipterainfo.nl/news.php?fam=Dolichopodidae (Accessed: 28 May 2018)

PaPe T., Blagoderov V., Mostovski M.B. 2011. Order Diptera Linnaeus, 1758. [in;] Z.Q. Zhang (ed.). Animal biodiversity: an outline of higher-level classification and survey of taxonomic richness. Zootaxa, 3148: 222-229. 
PARENT O. 1925. Contribution à la faune diptérologique d'Égypte. Bulletin de la Société Royale Entomologique d'Égypte, 9: 153-185.

PARENT O. 1929. Contribution à la faune diptérologique d'Égypte: Dolichopodides de la région de Halaib. Bulletin de la Société Royale entomologique d'Égypte, 13: 42-58.

PARENT O. 1938. Diptères Dolichopodidae. Faune de France, 35. Lechevalier, Paris.

Pollet M. 2001. Dolichopodid biodiversity and site quality assessment of reed marshes and grasslands in Belgium (Diptera: Dolichopodidae). Journal of Insect Conservation, 5 (2): 99-116.

Pollet M. 2004. Fauna Europaea: Dolichopodidae, version 1.0, 27 September 2004 [in:] Fauna Europaea: Diptera, Brachycera, version 2.6. Internet: http://www.faunaeur.org (Accessed: 5 September 2018)

Poulding R.H. 1998. The larvae of Aphrosylus celtiber HaLIDAY (Diptera, Dolichopodidae) as predators of the littoral barnacle Chthamalus montagui SOUTHWARD (Cirripedia, Chthamalidae). Dipterist's Digest (Second Series), 5: 70-74.

Robinson H., Vockeroth J.R. 1981. 48. Dolichopodidae. [in:] J.F. McAlpine, B.V. Peterson, G.E. Shewell, H.J. Teskey, J.R. Vockeroth, D.M. Wood (eds.). Manual of Nearctic Diptera. Research Branch, Agriculture Canada, Monograph, 27 (1), 625-639.

Roubaud E. 1903. Sur les larves marines de Dolichopodes attribués au genre Aphrosylus (WLKR). Bulletin du Musée d'Histoire Naturelle, Paris, 9: 338-340.

SAUNDERS L.G. 1928. Some marine insects of the Pacific Coast of Canada. Aphrosylus praedator WH. Annals Entomological Society of America, 21: 540-542.

SMITH K.G.V. 1989. An introduction to the immature stages of British flies. Handbooks for the Identification of British Insects. Vol. 10, Part 14. Royal Entomological Society of London, London.

Teskey H.J. 1981. Morphology and terminology - Larvae. [in:] J.F. MCAlPine, B.V. Peterson, G.E. Shewell, H.J. Teskey, J.R. Vockeroth, D.M. Wood (eds.). Manual of Nearctic Diptera. Research Branch, Agriculture Canada, Monograph, 27 (1), 65-88.

WhEELER W.M. 1897. A genus of maritime Dolichopodidae new to America. Proceedings of the California Academy of Sciences, 3d ser., Zoology, 1 (4): 145-152.

WiLliams F.X. 1939. Biological studies in Hawaiian water-loving insects. Part III: Diptera or flies. B. Asteiidae, Syrphidae, and Dolichopodidae. Proceedings of the Hawaiian Entomological Society, 10 (3): 281-315, pls. XVI-XXI.

Received: 27 October 2018

Accepted: 30 November 2018 